https://helda.helsinki.fi

Leuconostoc gasicomitatum is the dominating lactic acid bacterium in retail modified-atmosphere-packaged marinated broiler meat strips on sell-by day

\title{
Susiluoto, Tuija
}

Elsevier

2002

International Journal of Food Microbiology. 2002. 80(1): 89-97

http://hdl.handle.net/1975/516

http://dx.doi.org/10.1016/S0168-1605(02)00123-X

Downloaded from Helda, University of Helsinki institutional repository.

This is an electronic reprint of the original article.

This reprint may differ from the original in pagination and typographic detail.

Please cite the original version. 
4

5

6

7 8

9

10

11

12

13

14

15

16

17

18

\title{
Leuconostoc gasicomitatum is the dominating lactic acid bacterium in retail modified-atmosphere-packaged marinated broiler meat strips on sell-by day.
}

\author{
Tuija Susiluoto*, Hannu Korkeala and Johanna Björkroth \\ Department of Food and Environmental Hygiene, Faculty of Veterinary medicine, University of \\ Helsinki, Helsinki, Finland
}

Key words

Lactic acid bacteria, Leuconostoc gasicomitatum, MAP, broiler, spoilage, ribotyping

*Corresponding author: Department of Food and Environmental Hygiene, Faculty of Veterinary

Medicine, University of Helsinki, P.O. Box 57, FIN-00014 Helsinki University, Finland.

Phone: +358-9-19149701, fax: +358-9-19149718, e-mail: tuija.susiluoto@helsinki.fi 
3 Lactic acid bacteria (LAB) in retail, modified-atmosphere-packaged (MAP), marinated broiler meat

4 strips on sell-by day were mainly identified as Leuconostoc gasicomitatum. A total of 32 packages,

53 to 5 packages of 7 differently marinated broiler meat products, were studied at the end of the 6 producer-defined shelf life (at $6^{\circ} \mathrm{C}, 7$ to 9 days depending on the manufacturer). Prior to the 7 microbiological analyses, appearance and smell of the product was checked and $\mathrm{pH}$ measured. 8 Bacteria were cultured on MRS and Tomato Juice Agar (TJA), Rogosa SL agar (SLA), Plate Count 9 Agar (PCA) and Streptomycin Thallium Acetate Agar (STAA) for the enumeration of LAB, 10 lactobacilli, total bacterial count and B. thermosphacta, respectively. The average CFU/g of the 32 11 packages was $2.3 \times 10^{8}$ on PCA. The highest bacterial average, $3.1 \times 10^{8}$, was recovered on TJA, 12 the corresponding CFU/g averages on MRS and SLA being $2.3 \times 10^{8}$ and $1.3 \times 10^{8}$, respectively. 13 Despite the high LAB numbers, radical spoilage changes such as unpleasant odor, slime production 14 and formation of gas were not recognized. B. thermosphacta did not form a significant part of the 15 bacterial population since none of the levels exceeded the spoilage threshold level of $10^{5} \mathrm{CFU} / \mathrm{g}$ 16 reported in previous studies. In order to characterize the dominating LAB population, as many as 1785,85 and 88 colonies from MRS, TJA and SLA, respectively, were randomly picked and cultured pure. LAB were identified to species level using a 16 and 23S rDNA HindIII RFLP (ribotyping) database. Fifty-six of the 170 isolates picked from the non-selective LAB media (MRS and TJA) were identified as Leuconostoc gasicomitatum, followed by Carnobacterium divergens (41 21 isolates), Lactobacillus sakei and Lactobacillus curvatus subsp. melibiosus (31 isolates) and 22 Lactobacillus curvatus subsp. curvatus (20 isolates) species. SLA proved not to be completely 23 selective for lactobacilli because the growth of Leuconostoc spp. was not inhibited, Carnobacterium 24 spp. were the only species not detected on SLA. 


\section{Introduction}

Lactic acid bacteria (LAB) and Brochothrix thermosphacta are the main spoilage organisms in vacuum or modified atmosphere packaged (MAP) meat and meat products (Egan, 1983; Korkeala, 1987; von Holy et al., 1991; Borch et al., 1996, a review; Jay, 1996; Taylor, 1996; Hansen and Bautista, 2000; Nychas and Drosinos, 2000). Lactobacillus spp., Leuconostoc spp. and Carnobacterium spp. have mainly been associated with the spoilage of these products (Schillinger and Lücke 1987, Korkeala et al., 1988; Borch and Agerhem, 1992; Dainty and Mackey, 1992; Borch et al., 1996, a review; Björkroth et al. 1998). MAP broiler (young fowl) meat products are consumed increasingly in Finland for they are low in fat and easy to cook. In 2000, $13.3 \mathrm{~kg}$ of poultry meat were consumed per capita in Finland, which is about 50\% more than in 1990. Most of the broiler meat is sold MAP and marinated in Finland. Marinating means here mixing the meat with water-oil-based, spiced sauces and these products have a wide diversity varying from carcass cuts to skinned fillet strips. Consumers can use the marinated products as such without further spicing which results in a very convenient way of making a meal.

Despite the increasing popularity of MAP, marinated broiler meat products, only few studies of the levels and species of LAB (Björkroth et al., 2000) or Brochothrix thermosphacta in these products have been carried out. Tomato based products, such as many of the marinades, have generally been found susceptible to spoilage by LAB (Juven and Weisslowich, 1981; Porretta and Vicini, 1993; Björkroth and Korkeala, 1997). A severe LAB spoilage was faced in a tomato-marinated broiler meat product packaged under $\mathrm{CO}_{2}(80 \%)$ and $\mathrm{N}_{2}(20 \%)$ (Björkroth, et al. 2000). These tomato marinated broiler meat strips were spoiled in 5 to 6 days at $6^{\circ} \mathrm{C}$ by a LAB population which produced unpleasantly smelling compounds, and also formed large amounts of gas. This resulted in severe bulging of the packages and withdrawal of the product from the market. A novel LAB species was found to predominate in these spoiled products and it was named as Leuconostoc gasicomitatum. This name was validated in 2001 (Anonymous).

The purpose of this study was to determine which LAB species dominate the microflora of MAP, marinated broiler meat strips in retail products which do not yet show clear spoilage changes at the end of the producer-defined shelf life. The microbial quality was as well evaluated and different media suitable for the determination of LAB levels were compared. L. gasicomitatum strains were found to dominate in these products and Carnobacterium divergens, Lactobacillus sakei subsp. 
1 sakei and Lactobacillus curvatus subsp. curvatus were the next common species detected. LAB

2 levels were high on all three selective media used whereas B. thermosphacta did not form a 3 significant part of the bacterial population.

4

5

6

7

8

\section{Materials and methods}

\subsection{Packages}

MAP broiler meat strips were purchased from retail dealers. The upper limit for storage temperature of meat kept for sale in retail shops in Finland is $6^{\circ} \mathrm{C}$. After purchase the packages were immediately brought to our laboratory and, if necessary, stored at $6^{\circ} \mathrm{C}$ until the sell-by-day. Products from three different large-scale manufacturers were included. The typical MA for broiler meat containing $80 \% \mathrm{CO}_{2}$ and $20 \% \mathrm{~N}_{2}$ had been used by all manufacturers. Altogether 32 packages of 7 differently marinated products were studied, 3 to 5 packages of each product. The products consisted of skinned breast fillet, which had been mixed with the marinade and packaged under MA conditions. The marinades contained different spices but common ingredients in all were water, vegetable oil, sucrose or glucose, citric or acetic acid, sodium chloride (0.7 to $1.3 \%)$, potassium sorbate, sodium benzoate, xanthan gum and guar gum.

\subsection{Sample preparation for the microbial analysis}

Prior to the microbiological analysis, the odor, texture and $\mathrm{pH}$ of meat was checked and notice was paid to the amount of gas in each package. The purpose of checking of odor and appearance was to assure that none of the packages studied were showing clear signs of spoilage due to leaking etc and were therefore possessing typical late shelf life quality. On the sell-by day ( $\pm 1 \mathrm{~d}$ ) a sterile $22 \mathrm{~g}$ sample was homogenized in $198 \mathrm{~g}$ of $0.1 \%$ peptone water using a Stomacher blender (NCFA, 1988). Serial 10 -fold dilutions of the homogenized samples were made from $10^{-2}$ to $10^{-8}$ in $0.1 \%$ peptone water.

\subsection{Aerobic plate count}

Aerobic plate count was done on Plate Count Agar (PCA) (Difco laboratories, Detroit, USA) using the pour plate technique and the medium was incubated for $3 \mathrm{~d}$ in aerobic atmosphere in accordance with the NCFA method (1989) with the exception of incubating the plates at $25^{\circ} \mathrm{C}$. Incubation at 
$125^{\circ} \mathrm{C}$ is adequate for both Lactobacillus and Leuconostoc genera (Batt, 2000; Lonvaud-Funel, 2 2000).

\subsection{Enumeration of $L A B$}

In order to show culture medium related effects on the enumeration of $\mathrm{LAB}, \mathrm{CFU} / \mathrm{g}$ was determined by parallel plating of the samples on MRS Agar (Oxoid, Basingstoke, England), Tomato Juice Agar (TJA, Oxoid) and Rogosa SL agar (SLA, Difco). MRS Agar supports the growth of all LAB (Reuter, 1985; Baird et al., 1987; Holzapfel, 1992, a review). TJA was chosen to in order to show how LAB associated with marinades grow on a tomato-based medium. Many of these marinades contain tomato pure and tomato is known to stimulate the growth of some LAB (Garvie and Mabbitt, 1967). According to the manufacturer, SLA is a selective medium for culturing of lactobacilli. Acetic acid content and low pH in SLA is supposed to prevent the growth of other LAB (Reuter, 1985; Baird et al., 1987; Holzapfel, 1992, a review). The media were inoculated using the spread plate technique and all plates were incubated in an anaerobic $\mathrm{CO}_{2}$ atmosphere (Anaerogen, Oxoid, $9-13 \% \mathrm{CO}_{2}$ according to the manufacturer) at $25^{\circ} \mathrm{C}$ for 5 to 6 days.

\subsection{Detection of $B$. thermosphacta}

B. thermosphacta was detected using the Streptomycin Thallium Acetate Agar (STAA) medium (Oxoid, Basingstoke, England). Plates were incubated at $25^{\circ} \mathrm{C}$ for 2 to 3 days aerobically in accordance with the NCFA method (1991). Pseudomonas spp. was ruled out by performing the oxidase test (Baird et al., 1987; NCFA, 1991) with 1\% N,N-phenylenediammonium dichloridesolution (Tamro Lab, Vantaa, Finland).

\subsection{Selection and management of LAB for species identification}

From each sample, 1 to 3 randomly picked colonies from the three LAB media (MRS, TJA and SLA) were tested for growth in MRS broth (Difco) at $25^{\circ} \mathrm{C}$ for one to two days. Inoculation of all randomly selected colonies into MRS broth resulted in growth. MRS broth and agar were subsequently used for further propagation of the strains. A total of 85,85 and 88 colonies from MRS, TJA and SLA media, respectively, were cultured pure. Altogether 258 LAB isolates were submitted to species level identification. For DNA extraction, MRS broth was inoculated and the tubes were grown at $25^{\circ} \mathrm{C}$ for one to two days depending on the growth rate. After incubation, cells harvested from $1.5 \mathrm{ml}$ of MRS broth were used for DNA extraction. The isolates were stored in MRS broth at $-70^{\circ} \mathrm{C}$. 


\section{$2 \quad 2.716$ and $23 S$ rDNA HindIII RFLP, Ribotyping}

3 DNA was isolated using a modified (Björkroth and Korkeala, 1996) guanidium thiocyanate method 4 of Pitcher et al. (1989). In this modification, the cell lysis solution contains mutanolysin (250 U/ml, 5 Sigma, St. Louis, Missouri) in addition to lysozyme (25 mg/ml, Sigma). Restriction endonuclease 6 treatment of $8 \mu \mathrm{g}$ of DNA was done using HindIII restriction enzyme (New England Biolabs, 7 Beverly, Mass., USA) as specified by the manufacturer. HindIII was chosen because it has been found to provide species-specific patterns for various spoilage LAB (Björkroth and Korkeala, 1996a, 1997; Björkroth et al., 1998, 2000). REA was performed as described before (Björkroth and Korkeala, 1996). Genomic blots were made using a vacuum device (Vacugene, Pharmacia, Uppsala, Sweden) and the rDNA probe for ribotyping was labeled by reverse transcription (AMVRT, Promega, Madison, Wisc., USA and Dig DNA Labeling Kit, Roche Molecular Biochemicals, Mannheim, Germany) as previously described by Blumberg et al. (1991). Membranes were hybridized at $58^{\circ} \mathrm{C}$ overnight and the detection of the digoxigenin label was performed as recommended by Roche Molecular Biochemicals.

\subsection{Numerical analysis of HindIII ribopatterns}

The membranes were scanned with a Hewlett-Packard ScanJet 4c/T tabletop scanner (Boise, Idaho, USA). Numerical analysis of the ribopatterns was performed using the Bionumerics 2.0 software package (Applied Maths, Kortrijk, Belgium). Based on internal controls, 1.5\% position tolerance and $0.5 \%$ optimization was allowed for the bands/patterns. The similarity between all pairs was expressed by Dice coefficient correlation, and the unweighted pair-group method with arithmetic averages (UPGMA) was used for the construction of the dendrogram. The ribopatterns were compared with the corresponding patterns in the LAB database at the Department of Food and Environmental Hygiene, University of Helsinki, Finland. It comprises patterns of all relevant spoilage LAB in the genera of Carnobacterium, Lactobacillus, Leuconostoc, Enterococcus and Weissella (Björkroth and Korkeala, 1996b, 1997; Björkroth et al., 1998, 2000; Lyhs et al., 1999). Identification of the isolates was made on the basis of locations of the type strains in the clusters.

\section{Results}


1 total flora. Five of the seven products studied showed growth at levels higher or close to $10^{8} \mathrm{CFU} / \mathrm{g}$.

2 The $\mathrm{pH}$ of the samples was from 4.9 to 5.9 , the average $\mathrm{pH}$ being 5.6 (Table 1). LAB were best

3 recovered on TJA agar. When the average enumeration levels $(\mathrm{CFU} / \mathrm{g})$ of all 32 packages are

4 compared, $57.1 \%, 25.3 \%$ and $24.1 \%$ less grew on SLA, PCA and MRS, respectively, than on TJA.

5

6

The dominating LAB species in MAP, marinated broiler meat strips was L. gasicomitatum and these strains were detected in the products of all producers and in six of the seven marinades (Table 2). Fifty-six isolates possessed patterns (Ia to Id, Fig. 1) similar to or identical with the ribotype of L. gasicomitatum type strain. L. gasicomitatum cluster was homogenous and it could be divided into four subclusters consisting of strains (ribotypes Ia, Ib, Ic and Id) having a similarity higher than $80 \%$. Most $L$. gasicomitatum strains possessed identical ribopatterns with the L. gasicomitatum type strain LMG 18811 (ribotype Ia). The two almost similar ribotypes Ib and Ic differed from the type strain Ia by one fragment only. Ribotype Id missed one fragment compared to pattern of the $L$. gasicomitatum type strain (Ia, Fig. 1). L. gasicomitatum strains had a similarity of $50 \%$ compared to the Leuconostoc mesenteroides cluster which diverged closest to the L. gasicomitatum cluster (Fig 1.). Initially, L. gasicomitatum strains were recovered more often from TJA $(58,9 \%$ of $L$. gasicomitatum strains originated from TJA) than from MRS agar (41.1\% of L. gasicomitatum strains originated from MRS). L. gasicomitatum strains also grew on SLA.

Leuconostocs branched separately from the other LAB and were well demarked as their own genus (Fig. 1). Fourteen isolates possessed identical patterns with Leuconostoc ribotypes V, VI and VII (Fig. 1, Table 3). Two strains had identical ribopatterns with L. mesenteroides type strain (ribotype V), 10 strains with Leuconostoc carnosum type strain (ribotype VI) and 2 strains with Leuconostoc gelidum type strain (ribotype VII). L. mesenteroides, L. carnosum and L. gelidum strains were found in five of the seven packages and they were also detected on SLA.

At the genus level, lactobacilli were the most prevalent and as many as 53 isolates possessed ribotypes IIa, IIb, IIc, IId, IVa, IVb, IVc and IVd (Fig. 1, Table 3). The patterns of 24 isolates were identical with $L$. sakei ribotypes IVb, IVc and IVd, 22 were identical with L. curvatus subsp. curvatus ribotypes IIa, IIb, IIc and IId and 7 were identical with L. curvatus subsp. melibiosus ribotype IVa (Table 3). L. curvatus subsp. melibiosus ribotype IVa and L. sakei subsp. sakei ribotype IVc clustered together with a similarity over 90\%, as reported before by Lyhs et al. (1999). L. sakei subsp. carnosum ribotype IVb was as well branched close to L. sakei subsp. sakei and L. curvatus subsp. melibiosus type strains. L. curvatus subsp. curvatus ribotypes IIa, IIb and IIc 
1 formed a clearly distinct cluster with a low level of similarity (20\%) to the other LAB. Ribotype

2 IVd was a common finding within the L. sakei subspecies. Isolates identical with the ribotype IVd had a one-band difference to L. sakei subsp. carnosum type strain (Fig 1.). Bacteria belonging to the genus Lactobacillus were detected in all packages studied (Table 2).

Forty-one isolates showed ribotypes IIIa, IIIb and IIIc similar to the ribotype of $C$. divergens type strain. The pattern of one isolate (ribotype $\mathrm{IXb}$ ) was similar to the ribotype of Carnobacterium piscicola (IXa) (Fig 1, Table 3). Carnobacteria did not grow on SLA and were detected only in marinated products B1, B2 and B3 (Table 2). The species of four isolates on nonselective media and seven isolates on SLA remained unidentified. They possessed ribotypes X, XI, XII, XIII (Fig. 1).

\section{Discussion}

L. gasicomitatum was the dominating LAB species in MAP, marinated broiler meat products not yet showing signs of spoilage at the end of shelf life. LAB levels were relatively high, $10^{6}$ to $10^{8}$ $\mathrm{CFU} / \mathrm{g}$ in all samples whereas the levels of $B$. thermosphacta did not exceed $10^{5} \mathrm{CFU} / \mathrm{g}$ previously reported as the spoilage threshold level (Holley, 2000). Fifty-\% carbon dioxide MA inhibits the growth of $B$. thermosphacta (Holt et al., 1994; Holley, 2000). The initial $\mathrm{CO}_{2}$ level in these products was $80 \%$ apparently providing unfavorable circumstances for $B$. thermosphacta or the contamination level with this organism was low in these products. In addition to L. gasicomitatum, Lactobacillus sakei and curvatus spp. were frequently detected.

L. gasicomitatum species has been described by Björkroth et al. (2000) and it was assumed to be a specific spoilage organism in, MAP, tomato-marinated broiler meat strips showing a gaseous spoilage type. Higher numbers of L. gasicomitatum was detected in the spoiled samples $(55,8 \%$ of isolates on MRS) than in these late shelf life samples (32,9\% of isolates on MRS and TJA). Therefore, the growth of L. gasicomitatum in MAP marinated broiler meat strips is likely to result in spoilage and L. gasicomitatum can be considered as a specific spoilage organism in these products. L. carnosum, L. mesenteroides subsp. mesenteroides and L. gelidum strains were detected only in small amounts and they do not probably play a major role in the spoilage of marinated broiler meat products. In addition to the leuconostocs, L. sakei and L. curvatus strains were commonly (31.2\% of the isolates on nonselective media) detected. These species were also associated with the spoiled tomato-marinated broiler product (Björkroth et al. 2000), where they 
1 formed $40 \%$ of the spoilage flora recovered from MRS medium. Carnobacteria were not detected at

2 all in the spoiled samples (Björkroth et al. 2000) whereas $C$. divergens was a common finding in these late shelf life samples although it was not found in all packages. According to Barakat et al. (2000), C. divergens belongs also to the microflora of cooked, refrigerated MAP poultry meat.

Egan (1983) stated that the number of LAB in a sample is usually equal to the number of bacteria on a nonselective media, such as PCA. In our study, somewhat lower CFU/g counts were obtained using PCA or MRS instead of TJA. The fact that L. gasicomitatum and other leuconostocs were more frequently recovered from TJA corresponds to the finding that the growth of some leuconostocs is supported by factors existing in tomato juice (Garvie and Mabbitt, 1967). In case of this leuconostoc-rich population this may have been the reason for the detection of highest bacterial CFU levels on TJA. MRS does not apparently support the growth of all L. gasicomitatum strains during the initial recovery even the strains can later be cultivated using this medium. It was also shown clearly that SLA is not a selective agar suitable for determining the number of Lactobacillus spp. All Leuconostoc species detected in this study were also recovered from SLA.

According to our study, relatively high levels of LAB are found in the marinated products already after 7 to 9 day's storage, during which marinated MAP broiler meat strips are to be sold. Vacuum packaged red meat and poultry products have shown spoilage when LAB levels reach $10^{7}$ (Korkeala et al., 1987; Von Holy et al., 1991; Sawaya et al., 1993). The expected shelf life for red meat products under refrigerated storage in a combined $\mathrm{CO}_{2}$ and $\mathrm{N}_{2}$ atmosphere is over weeks (Borch et al., 1996, a review). Results concerning the shelf life of un-marinated chicken products give a reason to suspect that also these products have a longer shelf life than the marinated products (Gill et al., 1990; Kakouri and Nychas, 1994; Nychas and Tassou, 1997). LAB reached only $1.8 \times 10^{6}$ $\mathrm{CFU} / \mathrm{g}$ in $100 \% \mathrm{CO}_{2}$-atmosphere when stored at $3{ }^{\circ} \mathrm{C}$ for 12 days (Nychas and Tassou, 1997). The chicken carcasses packaged under $100 \% \mathrm{CO}_{2}$ studied by Gill et al. (1990) had approximately the same total amount of bacteria than in our study. However, these carcasses (Gill et al.,1990) had been stored for four weeks at $3^{\circ} \mathrm{C}$. The carcasses were considered spoiled only in the seventh storage week, when the bacterial numbers had reached $6.4 \times 10^{9} \mathrm{CFU} / \mathrm{g}$ (Gill et al., 1990). When a MAP tomato-marinated broiler meat strip product was showing gaseous spoilage, the LAB numbers had risen up to $10^{10} \mathrm{CFU} / \mathrm{g}$ (Björkroth et al., 2000).

Because high $\mathrm{CFU} / \mathrm{g}$ values were obtained from the products possessing both high (in this case $\mathrm{pH}$ 5.9) or low ( $\mathrm{pH} 4.9) \mathrm{pH}$ values, no association of the $\mathrm{pH}$ with the microbial product quality can be 
1 made. The initial acidity of the marinades is high but the meat buffers the $\mathrm{pH}$ quite rapidly.

2 Compared to the spoilage of pork or beef products, the spoilage flora of marinated broiler meat

3 seems to be quite different. L. gasicomitatum strains have yet been detected only in broiler meat

4 products despite numerous studies of beef and pork products. In marinating, the initial LAB contamination of broiler meat and the marinade is combined and the ecological niche of the final product results from this combination. LAB growth and spoilage associated with marinated broiler meat is therefore a more complex event than in a "plain meat product". Even sensory panel was not used during this study we also noticed that it was difficult to evaluate the odour of the different products. Marinades apparently mask some of the early spoilage effects.

Both consumers and producers would benefit from better understanding of the effects the marinades have on the developing LAB population and shelf life of broiler meat products. Now when the species distribution in different marinades is known, we are able to study further the interaction between various LAB and the role of the marinade ingredients in the spoilage. This will be aim of our further studies.

\section{Conclusion}

L. gasicomitatum was found to be the dominating LAB in retail, MAP, marinated broiler meat strips on sell-by day. In addition, C. divergens, L. sakei subsp. sakei and L. curvatus subsp. curvatus were the next common species detected. LAB levels were high on all three selective media used whereas B. thermosphacta did not form a significant part of the bacterial population.

\section{References}

Anonymous (2001) Validation list no.79. Int. J. System. Evol. Microbiol. 51, 263-265.

Baird, R. M. , Corry, J. E. L. and Curtis, G. D. W. (Ed.) (1987) Pharmacopoeia of culture media for food microbiology. De Man, Rogosa and Sharpe (MRS) agar. Int. J. Food Microbiol. 5, 228-229.

Barakat, R. K., Griffits M. W. and Harris, L. J. (2000) Isolation and characterization of Carnobacterium, Lactococcus, and Enterococcus spp. from cooked, modified atmosphere packaged, refrigerated, poultry meat. Int. J. of Food Microbiol. 62, 83-94.

Batt, C. A. (2000) Lactobacillus, Introduction. In: Robinson, K., Batt, C. A. and Patel, P. D. (Ed.). Encyclopedia of Food Microbiology 2, Academic press, Bath, pp. 134-136. 
Björkroth, J. K.; Geisen, R.; Schillinger, U.; Weiss, N.; de Vos, P.; Holzapfel, W. H.; Korkeala, H. J. and Vandamme, P. (2000) Characterisation of Leuconostoc gasicomitatum sp. nov. associated with spoiled raw tomato-marinated broiler meat strips packaged under modified atmosphere conditions. Appl. Environ. Microbiol. 66, 3764-3772.

Björkroth, J. K.; Vandamme, P. and Korkeala, H. J. (1998) Identification and Characterization of Leuconostoc carnosum, Associated with Production and Spoilage of VacuumPackaged, Sliced, Cooked Ham. Appl. Environ. Microbiol. 64, 3313-3319.

Björkroth, J. K. and Korkeala, H. K. (1997) Lactobacillus fructivorans spoilage of tomato ketchup. J. Food Prot. 60, 505-509.

Borch, E. and Agerhem, H. (1992) Chemical, microbial and sensory changes during the anaerobic cold storage of beef inoculated with a homofermentative Lactobacillus sp. or a Leuconostoc sp. Int. J. Food Microbiol. 15, 99-108.

Borch, E., Berg, H. and Holst, O. (1991) Heterolactic fermentation by a homofermentative Lactobacillus sp. during glucose limitation in anaerobic continuous culture with complete cell recycle. J. Appl. Bacteriol. 71, 265-269.

Borch, E., Kant-Muermans, M-L. and Blixt, Y. (1996) Bacterial spoilage of meat and cured meat products. A review. Int. J. Food Microbiol. 33, 103-120.

Dainty, R. H. and Mackey, B. M. (1992) The relationship between the phenotypic properties of bacteria from chill- stored meat and spoilage processes. J. Appl. Bacteriol. 73, 103S-114S.

Egan, A. F. (1983) Lactic acid bacteria of meat and meat products. Antonie van Leeuwenhoek 49, 327-336.

Garvie, E. and Mabbitt, L. A. (1967) Stimulation of the Growth of Leuconostoc oenos by tomato juice. Archiv für Mikrobiologie 55, 398-407.

Gill, C. O. , Harrison, J. C. L. and Penney, N. (1990) The storage life of chicken carcasses packaged under carbon dioxide. Int. J. Food microbiol. 11, 151-158.

Hansen, K. M. J. and Bautista, D. A. (2000). Spoilage problems, problems caused by bacteria. In: Robinson, K. , Batt, C. A. and Patel, P. D. (Ed.). Encyclopedia of Food Microbiology 3, Academic press, Bath, 2051-2056.

Holley, R. A. Brochothrix. (2000) In: Robinson, K. , Batt, C. A. and Patel, P. D. (Ed.). Encyclopedia of Food Microbiology, vol 1, Academic press, Bath, 314-318.

Holzapfel, W. H. (1992) Culture media for non- sporulating Gram- positive food spoilage bacteria. A review. Int. J. Food Microbiol. 17, 113- 133.

Holt, J. G., Krieg, N. R., Sneath, P. H. A., Staley, J. T. and Williams, S. T. (1994) Bergeys Manual of Determinative Bacteriology, 9th edn., Williams \& Wilkins, Baltimore, pp. 787. 
Jay, J. M. (1996) Modern Food Microbiology. 5th edn., Chapman \& Hall, New York, pp. 661.

Jones, M. V. (1989) Modified atmospheres. In: Gould, G. W. (Ed.). Mechanisms of Action of Food Preservation Procedures. Elsevier Applied Science, Essex, 247-277.

Juven, B. and Weisslowitch, H. (1981) Chemical changes in tomato juices caused by lactic acid bacteria. J. Food Sci. 46, 1543-1545.

Kakouri, A. and Nychas, G. J. E. (1994) Storage of poultry meat under modified atmospheres or vacuum-packs. Possible role of microbial metabolites as indicator of spoilage. J. Appl. Bacteriol. 76, 163-172.

Korkeala, H. , Ahvenainen, R. and Alanko, T. (1987) Interrelationship between microbial numbers and other parameters in the spoilage of vacuum-packed cooked sausages. Int. J. Food Microbiol. 5, 311-321.

Korkeala, H., Suortti, T. and Mäkelä, P. (1988) Ropy slime formation in vacuum-packed cooked meat products caused by homofermentative lactobacilli and Leuconostoc species. Int. J. Food Microbiol. 7, 339-347.

Lonvaud-Funel, A. (2000) Leuconostoc. In: Robinson, K. , Batt, C. A. and Patel, P. D. (Ed.). Encyclopedia of Food Microbiology 2, Academic Press, Bath, 1183-1194.

Lyhs, U., Björkroth, J. and Korkeala, H. (1999) Characterisation of lactic acid bacteria from spoiled, vacuum-packaged, cold-smoked rainbow trout using ribotyping. Int. J. Food Microbiol. 52, 77-84.

NCFA, Nordic Committee on Food Analysis. Pretreatment of foods for microbiological examination. Method no 91, 1988.

NCFA, Nordic Committee on Food Analysis. Psychrotrophic microorganisms. Determination by the plate count method. Proposed method no 74, 2, 1989.

NCFA, Nordic Committee on Food Analysis. Brochothrix thermosphacta, determination in meat and meat products. Method no 141, 1991.

Nychas, G. J. E. and Drosinos, E. H. (2000) Spoilage of meat. In: Robinson, K., Batt, C. A. and Patel, P. D. (Ed.). Encyclopedia of food microbiology 2, Academic Press, Bath, 1253-1260.

Nychas, G. J. E. and Tassou, C. C. (1997) Spoilage processes and proteolysis in chicken as detected by HPCL. J. Sci. Food Agric. 74, 199-208.

Porretta, S. and Vicini, E. (1993) Changes in tomato pulp quality caused by lactic acid bacteria. Int. J. Food, Sci. and Technol. 28, 611-616.

Pitcher, D.G., Saunders, N.A., Owen, R.J., 1989. Rapid extraction of bacterial genomic DNA with guanidium thiocyanate. Lett. Appl. Microbiol. 8, 151-156. 
Reuter, G. (1985) Elective and selective media for lactic acid bacteria. Int. J. Food 2 Microbiol. 2, 55-68.

3

4 5

6

Samelis, J., Kakouri A. and Rementzis, J (2000) The spoilage microflora of cured, cooked turkey breasts prepared commercially with or without smoking. Int. J. of Food Microbiol. 56, 13343.

Sawaya, W. N. , Abu-Ruwaida, A. S. , Hussain, A. J., Khalafawi, M. S. and Dashti, B. H. (1993) Shelf-life of vacuum-packaged eviscerated broiler carcasses under stimulated market conditions. J. Food Safety 13, 305-321.

Schillinger, U. and Lücke, F. K. (1987) Lactic acid bacteria on vacuum-packaged meat and their influence on shelf life. Fleischwirtsch. 67, 1244-1248.

Taylor, S. A. (1996) Modified atmosphere packing of meat. In: Meat quality and meat packaging. Taylor, S. A., Raimundo, A., Severini M. and Smulders, J. M. ECCEAMST, Utrecht, 301-308.

Tseng, C-P. and Montville, T. J. (1990) Enzyme activities affecting end product distribution by Lactobacillus plantarum in response to changes in $\mathrm{pH}$ and $\mathrm{O}_{2}$. Appl. Environ. Microbiol. 56, 2761-2763.

von Holy, A. , Cloete, T. E. and Holzapfel, W. H. (1991) Quantification and characterisation of microbial populations associated with spoiled, vacuum-packed vienna sausages. Food Microbiol. 8, 95-104. 
1 TABLE 1. The averages of colony forming units (CFU) determined from the CFU/g results of 3 to 25 packages of 7 differently marinated broiler meat strip products packaged under modified 3 atmosphere.$$
5 \text { Type of }
$$

6 product

$\mathrm{CFU} / \mathrm{g}(\log 10)$ average value

7 (no. of

$$
8
$$

9

10

1

12

12

13

$$
15
$$

18

19 aMRS Agar (Oxoid, Basingstoke, England)

$20 \quad{ }^{\mathrm{b}}$ Tomato Juice Agar (Oxoid)

21 'Plate Count Agar (Difco laboratories, Detroit, USA),

$22 \quad{ }^{\mathrm{d}}$ Rogosa SL Agar (Difco)

$23 \quad{ }^{\mathrm{e}}$ The average of four samples 

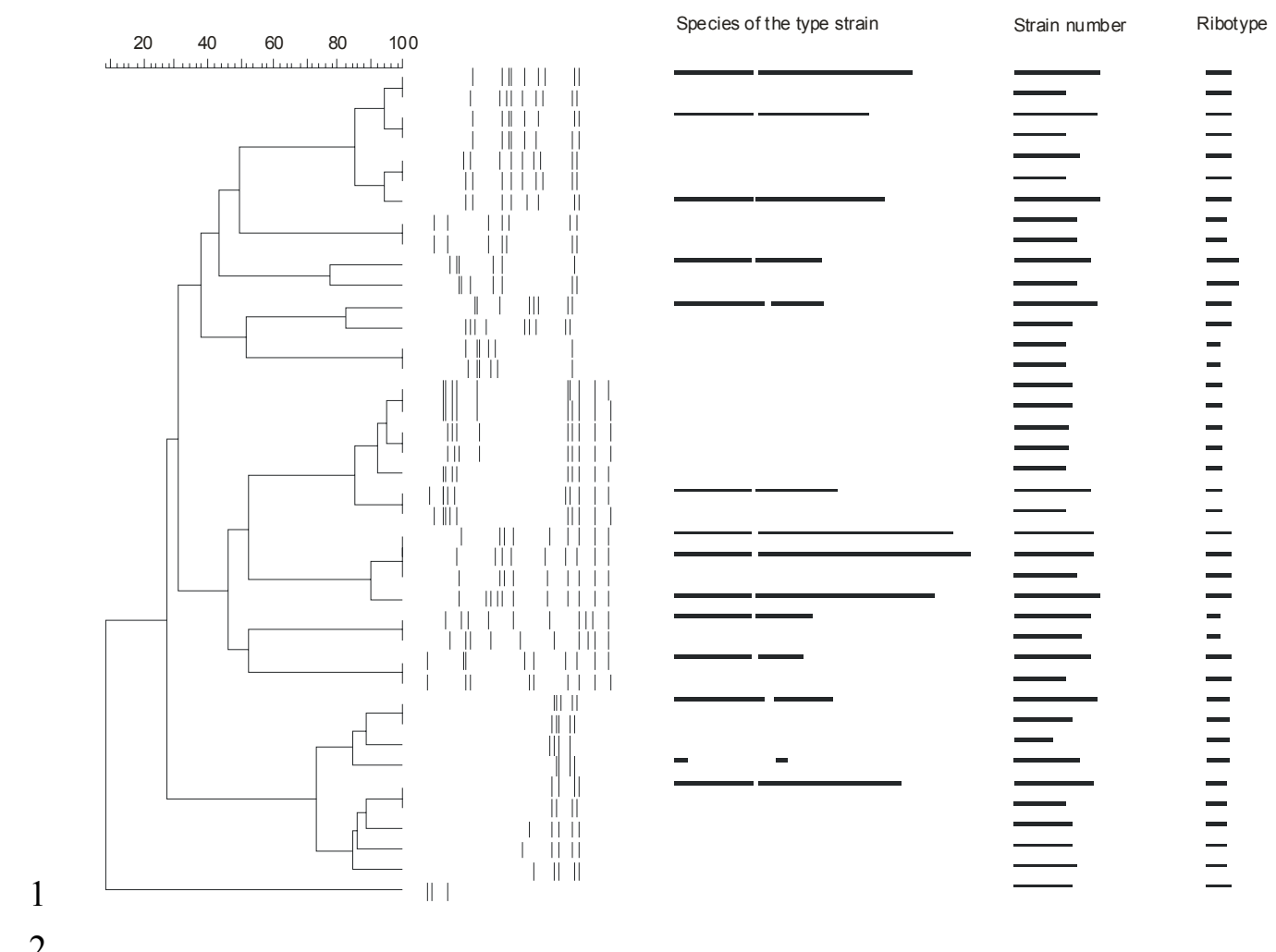

2

3 Fig. 1. Schematic patterns of HindIII ribopatterns and the numerical analysis of the patterns 4 presented as a dendrogram. Left side of the banding patterns, high molecular masses $<23 \mathrm{kbp}$ and 5 right the low molecular mass $>1000 \mathrm{bp}$. 